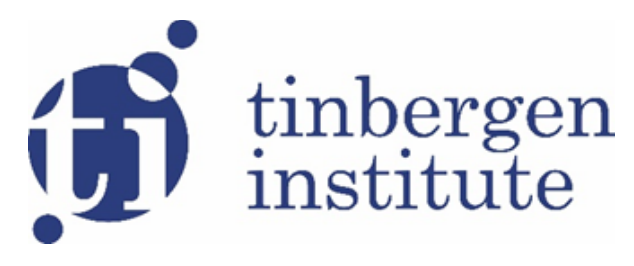

TI 2020-005/VII

Tinbergen Institute Discussion Paper

\title{
Event Studies in Merger Analysis: Review and an Application Using U.S. TNIC Data
}

Revision: March 2020

Timo Klein ${ }^{1}$ 
Tinbergen Institute is the graduate school and research institute in economics of Erasmus University Rotterdam, the University of Amsterdam and Vrije Universiteit Amsterdam.

Contact: discussionpapers@tinbergen.nl

More TI discussion papers can be downloaded at https://www.tinbergen.nl

Tinbergen Institute has two locations:

Tinbergen Institute Amsterdam

Gustav Mahlerplein 117

1082 MS Amsterdam

The Netherlands

Tel.: +31(0)205984580

Tinbergen Institute Rotterdam

Burg. Oudlaan 50

3062 PA Rotterdam

The Netherlands

Tel.: +31(0)10408 8900 


\title{
Event Studies in Merger Analysis: Review and an Application Using U.S. TNIC Data*
}

\author{
Timo Klein ${ }^{\dagger}$
}

March 2020

\begin{abstract}
There is a growing concern that U.S. merger control may have been too lenient, but empirical evidence remains limited. After reviewing event studies as a method to acquire empirical insights into the competitive effects of mergers, I propose a novel application using Hoberg-Phillips TNIC data. This application allows for the ready approximation of abnormal stock market returns of likely competitors to 1,751 of the largest U.S. mergers since 1997. I document that likely competitors experience on average an abnormal return of close to one percent around a merger announcement. Abnormal returns are also strongly associated with concerns of market power, which suggests that competitors benefit at least in part because of an anticipation of anti-competitive effects and hence insufficient merger control.
\end{abstract}

JEL Codes: G14, G34, L13, L40

Keywords: Mergers, Antitrust, Event Studies, Text-Based Network Industry Classification

*I am grateful for valuable comments from and discussions with Nuria Boot, Maurice Bun, Robin Döttling, Hans Friederiszick, John Kwoka, Maarten Pieter Schinkel and Florian Szücs and seminar participants at the Dutch Economist Day 2019 and the Dutch Authority for Consumers and Markets. Errors remain my own. See SSRN for the latest public working paper version.

${ }^{\dagger}$ Tinbergen Institute and Amsterdam School of Economics, University of Amsterdam. 


\section{Introduction}

A broad discussion has emerged on the observation of increased industry concentration, markups and market power (Autor, Dorn, Katz, Patterson and Van Reenen, forthcoming; Basu, 2019; De Loecker and Eeckhout, 2018; De Loecker, Eeckhout and Unger, forthcoming; Grullon, Larkin and Michaely, 2019; Syverson, 2019). One concern is that concentration and market power may have increased as a consequence of an insufficient deterrence of anti-competitive mergers, especially in the U.S. (Baker, 2019, p. 15; Gutiérrez and Philippon, 2018; Kwoka, 2015; Philippon, 2019; Shapiro, 2018; 2019; Wollmann, 2019). Despite the prominence of this concern, empirical evidence remains limited. In particular, ex post reviews of merger decisions remain complex or costly (and often politically unfavorable), and hence scarce. ${ }^{1}$

Event studies have been proposed as a simple alternative to acquire empirical insights into the anticipated competitive effects of mergers. By estimating the abnormal stock returns around an event date, event studies aim to identify the anticipated effect of this event on future firm performance. In the context of mergers, existing event studies look at the abnormal returns of competitors around a merger announcement. This follows from seminal microeconomic theory that predicts that competitors to a merger only benefit if anti-competitive effects from increased market concentration dominate, and only lose out if pro-competitive effects from merger efficiencies dominate (Farrell and Shapiro, 1990). Existing studies therefore often use as identifying assumption that an abnormal increase (decrease) in competitor stock price following a merger announcement indicates that financial markets anticipate the merger to be anti-competitive (pro-competitive). However, this inverse relationship between competitor stock price and consumer welfare is not guaranteed, as it may be weakened by the presence of other mechanisms as well as stock market noise.

This paper starts with a discussion on the use of event studies in merger analysis.

\footnotetext{
${ }^{1}$ For a review of existing work, see in particular Kwoka (2015). The relative absence of empirical evidence within Industrial Organization on the competitive effects of mergers is prominently criticized by Angrist and Pischke (2010, pp. 20-22).
} 
Existing studies generally suffer from the following limitations. First, the identifying assumption that abnormal competitor returns and consumer welfare are inversely related may fail to hold for various reasons and would have to be tested if used. Second, event studies in merger analysis require the reliable identification of competitors, which is often not obvious. And third, they involve the identification of small effects in very noisy data. This necessitates a sufficiently large dataset.

In a novel application of Hoberg-Phillips $(2010,2016)$ Text-Based Network Industry Classification (TNIC) data I am able to readily proxy a ranking of likely competitors to 1,751 U.S. mergers and acquisitions between 1997 and 2017 with a real transaction value above one billion dollar and a publicly-traded target. I document that likely competitors experience on average a positive and statistically significant abnormal return - with an estimated effect of up to one percent. I also find that abnormal returns show a strong positive association with a TNIC-based Herfindahl-Hirschman Index (HHI). Because HHI serves as an indicator of market power concerns, this association suggests that results are at least in part driven by an anticipation of anti-competitive market power effects, and hence an insufficient deterrence of anti-competitive mergers.

The remainder of this paper is as follows. Section 2 provides an overview of possible mechanisms through which a merger announcement may affect stock prices, reviews event studies in merger analysis and identifies and discusses the main challenges in using event studies in merger analysis. Sections 3 discusses the data collection and cleaning. Section 4 outlines the methodology used, Sections 5 discuss the results and Section 6 concludes.

\section{Review of Merger Event Studies}

Event studies are a well-developed method within finance and economics that aims to identify the anticipated effect of an event on firm performance (Fama, Fisher, Jensen 
and Roll, 1969; MacKinlay, 1997). Event studies are based on the efficient market hypothesis, which states that stock prices reflect all publicly available information on future profits. By estimating the abnormal stock returns around an event date, event studies aim to identify the anticipated effect of this event on future firm performance.

The estimation of abnormal return for a particular stock is generally done in the following three steps (MacKinlay, 1997). First, a linear relationship between stock and market return (the 'market model') is estimated during some estimation window prior to the event date. Usually, the estimation window lasts for around 250 days and stops several days before the event, so as to exclude any event effects in the estimation. Second, the abnormal return for each day around the event date is derived as the difference between actual stock return and the return as predicted by the market model. Third, the cumulative abnormal return from the event is derived as the sum of all daily abnormal returns during some event window - which is the range of days in which the new information has likely become public. This cumulative abnormal return is supposed to capture the anticipated effect from the event on future firm performance. Different event window specifications are often used for robustness.

Event studies have been used to analyze the anticipated effects of mergers by looking at the abnormal returns that occur around a merger announcement date. Below I first discuss the mechanisms through which a merger announcement may affect stock prices and how they relate to the anticipated competitive effects of the merger. I then review existing literature that aims to identify these mechanisms and close off with a review of the main challenges in using event studies in merger analysis.

\subsection{Mechanisms}

When using event studies in merger analysis, the identifying assumption that is often used is that a positive (negative) abnormal competitor return at the time of the merger announcement indicates an anticipation of anti-competitive (pro-competitive)

effects (Cichello and Lamdin, 2006). However, this identifying assumption may be 
weakened by the presence of other mechanisms. Below, the different mechanisms that may affect stock prices are discussed in more detail.

\subsubsection{Anticipated Efficiencies and Market Power Effects}

The inverse relationship between competitor return and consumer welfare follows from two opposing mechanisms within seminal microeconomic theory (Farrell and Shapiro, 1990): on the one hand, mergers generate cost efficiencies and other synergies that benefit the merging parties and consumers, but hurts competitors through reduced relative competitiveness; on the other hand, mergers increase unilateral market power of all market participants through a reduction in amount of firms active in the market. This benefits all firms, but hurts consumers. While merging firms benefit from both mechanisms, competitors lose out if the pro-competitive efficiency effect dominates and benefit if the anti-competitive market power effect dominates.

\subsubsection{Anticipated Exclusion Effects}

As also noted by Kwoka (2015, p. 42), a merger may also enable the merged entity to foreclose its competitor through predatory behavior or other exclusionary practices. An increased expectation of such behavior would lead to a negative abnormal competitor return, but driven by an anticipation of anti-competitive effects.

\subsubsection{In-Play or Out-of-Play Effects}

A merger may also signal that similar firms are "in play" and hence have an increased probability of being acquired in the future (Servaes and Tamayo, 2014; Song and Walkling, 2000). Because being acquired often involves a stock price premium, any increase in the acquisition probability would already cause the current stock price to increase. In principle, this mechanism can be either anti- or pro-competitive, as any future merger may again generate both anti- and pro-competitive effects. Contrasting this "in-play" effect is also a possible "out-of-play" effect, in which a 
merger announcement signals that competitors have lost a race to acquire the target (Fridolfsson and Stennek, 2010), or perhaps be acquired themselves.

\subsubsection{Signalling on Industry Health}

Additionally, a merger announcement may reveal positive information on market fundamentals, industry prospects or a general scope for efficiencies that was previously private. For instance, Derrien, Frésard, Slabik and Valta (2019) show that positive abnormal returns for industry peers occur in merger announcements when the target is a public firm, but not when it is a private firm. They argue that an acquirer who is assumed to be better informed on current and future industry performance - will prefer a public over a private firm when public firms are undervalued, all else equal. The acquisition of a public firm may therefore involve a signal that similar public firms are undervalued. This may cause competitors to experience a positive abnormal return even in the absence of any anticipated anti-competitive effects or "in-play" effects.

\subsubsection{Anticipated Change in X-Inefficiencies}

Furthermore, it may be claimed that the existence of a bigger, combined competitor increases the pressure on other firms to step up their game and reduce their own inefficiencies - subsequently increasing profit (at least partially). This relates to the idea of "X-inefficiencies", a concept described by Leibenstein (1966) to include all inefficiencies that follow from suboptimal performance enabled by insufficient competitive pressure. While difficult to exclude this mechanism, it is theoretically unclear exactly how a merger would increase (rather than decrease) competitive pressures, as it involves a reduction in the amount of firms active in the market. Additionally, empirical and theoretical evidence on X-inefficiency more generally remains mixed (see for instance Motta, 2004, pp. 47-48). 


\subsubsection{Acquirer Overbidding}

Finally, it is documented that in many cases acquiring firms experience a negative stock market reaction following a merger announcement (see for instance Moeller, Schlingemann and Stulz, 2005). Malmendier, Moretti and Peters (2018) discuss how this has been interpreted as evidence of incentive misalignment between managers and shareholders (for instance when managers are driven by empire building ambitions) or behavioral biases (such as CEO overconfidence). Conversely, if acquiring firms are inflicting self-harm, competing firms may actually benefit. Malmendier, Moretti and Peters indeed show that while stock returns of winners and losers in a bid to become the acquiring party closely track each other prior to the merger, losers outperform winners by 24 percent over the three years following the merger. If such "winning by losing" is anticipated by markets, competitors may witness a positive stock market response already upon announcement of the merger.

\subsubsection{Gradual Anticipation and Stock Market Noise}

Note finally that each mechanism may already be present prior to an official merger announcement when the merger is to some degree anticipated. In as far as the different mechanisms are affected differently by any anticipation, estimates of the abnormal returns may be biased when looking at returns too close to the official announcement. This requires a careful consideration of the event window.

Additionally, when financial markets believe that there is a probability that competition authorities will object to the merger, the effect of mechanisms that are conditional on the merger actually occurring may be discounted by the assumed probability of approval - conditional also on possible merger remedies.

Finally note that empirically, these mechanisms are generally obscured by the presence of stock market noise. This noise is amplified by the fact that firms are often large and diversified and the merger may only relate to one part of the business. 
Table 1: How Merger Announcements May Affect Stock Prices

\begin{tabular}{lccc}
\hline Mechanism & Target & Acquirer & Competitors \\
\hline Anticipated Efficiencies & + & + & - \\
Anticipated Market Power Effects & + & + & + \\
Anticipated Exclusion Effects & + & + & - \\
In-Play or Out-of-Play Effects & $\cdot$ & $\cdot$ & \pm \\
Signalling on Industry Health & + & + & + \\
Anticipated Change in X-Inefficiencies & \pm & \pm & \pm \\
Acquirer Overbidding & + & - & + \\
\hline
\end{tabular}

\subsection{Existing Literature}

Pioneering work on the use of event studies in merger analysis includes Stillman (1983), Eckbo (1983) and Eckbo and Wier (1985). Stillman (1983) looks at 11 U.S. horizontal mergers that occurred between 1964 and 1972 and were challenged by the competition authorities. Competitors are identified using opinions published in litigations or fact memoranda prepared by the competition authorities. Using a variation to the event study methodology mentioned above, he observes that in only one of these challenged mergers there is a positive abnormal competitor return around the time of the merger announcement, which he says suggests that U.S. competition authorities have challenged too many mergers.

Eckbo (1983) and Eckbo and Wier (1989) instead look at the average effect of a larger sample of up to 82 challenged U.S. horizontal mergers between 1963 and up to 1981. They use both SIC codes and public case summaries to identify competitors. Using event windows of up to 20 days prior and 10 days after the announcement, both studies find a positive and statistically significant average abnormal competitor return. However, they reject the hypothesis that this is driven by any anticipation of anti-competitive market power effects, because they do not observe the opposite result at the time of a merger challenge, which would have reduced the likelihood of merger approval. They suggest that the positive average abnormal competitor returns are instead driven by some signalling on the scope for competitors to improve 
performance. Fee and Thomas (2004) and Shahrur (2005) replicate these results for later periods, looking also at the effects on customers and suppliers.

These earlier studies have been criticized on several other grounds. First, their datasets are often limited to a few dozen mergers. Because using stock prices for merger analysis involves detecting small effects in noisy data, event studies have a very low precision in classifying individual mergers, or even small samples, as anti-competitive (Kwoka and Gu, 2015; McAfee and Williams, 1988; Werden and Williams, 1989a; 1989b). Second, they generally rely on industry codes such as SIC to identify competitors. This is problematic, because industry codes do a poor job at identifying antitrust markets (Werden, 1988; Hoberg and Phillips, 2016). Third, their event windows - often only a few days around the announcement - may be too restrictive, because an anticipation of a merger announcement may already occur much earlier (Duso, Gugler and Yurtoglu, 2010). And finally, these papers fail to test properly for the different possible mechanisms through which competitor stock prices are affected. For instance, they reject an anticipation of anti-competitive effects (despite the positive average abnormal competitor returns at the time of announcement) solely on the basis of an absence of statistically negative returns at the time of a merger challenge - which may simply be the consequence of low statistical power. Alternative explanations are suggested but not subjected to scrutiny.

Several more recent papers use event studies to analyze EU instead of U.S. merger control. These have the advantage over the earlier criticized work that they can reliably identify competitors to a large subset of EU mergers by using the published decisions by the European Commission - which is generally not available in the case of U.S. mergers. Instead of looking at the average abnormal competitor return (which these papers generally find is not statistically different from zero), they use the estimated abnormal returns to inform other policy questions.

More specifically, Duso, Neven and Röller (2007) look at 167 EU mergers between 1990 and 2002 and classify 46 as anti-competitive and 121 as pro-competitive - us- 
ing the inverse relationship between competitor stock prices and consumer welfare as identifying assumption and an event window of up to five days prior and after the announcement. They go on to explain how the EU institutional and political environment can explain false positive and negative. Duso, Gugler and Yurtoglu (2010) additionally show that a positive and statistically significant pairwise correlation coefficient exists between the estimated abnormal returns and ex post accounting profit, provided a sufficiently long event window of up to 50 days prior to the event is used. Duso, Gugler and Yurtoglu (2011), using an event window of 50 days prior and five days after the announcement, go on to show that EU merger control has been partially effective at reversing positive abnormal returns when they are observed correcting additionally for an estimated probability of antitrust interference. Finally, Duso, Gugler and Szücs (2013) extends these papers by looking at 368 EU mergers between 1990 and 2007. They also show how the 2004 merger reforms have partially improved EU merger control. ${ }^{2}$

For their approach, these papers require the classification of individual cases as either anti- or pro-competitive based on whether abnormal returns are positive of negative. Because of stock market noise, this approach may have a very low precision. Additionally, the existence of possible alternative mechanisms affecting the abnormal returns is acknowledged, but generally ignored in the analysis. For instance, Duso, Neven and Röller (2007) accept that merger announcements may signal a scope for competitor efficiencies as well as "in-play" or "out-of-play" effects. However, they argue that none of these mechanisms have a convincing empirical or theoretical basis and hence ignore them (pp. 462-464).

Finally, two recent papers use event studies to explicitly test for two of the other mechanisms. Firstly, Bernile and Lyandres (2019) show for 480 U.S. horizontal mergers between 1996 and 2005 a negative association between announced efficiencies and

\footnotetext{
${ }^{2}$ While not using event studies, Stiebale and Szücs (2019) also look at EU competitor performance - using micro panel data instead. They show for 194 EU mergers between 1999 and 2007 that competitors experience a statistically significant increase in estimated markups relative to a control, with larger estimates when market power concerns are more likely.
} 
abnormal competitor returns - in line with an anticipation of pro-competitive efficiencies. Competitors are identified using the SIC3-granularity TNIC provided by Hoberg and Phillips (2010, 2016), providing on average 12.5 competitors per merger, and they use an event window of up to 20 days prior and after the event. While they do report positive average abnormal competitor returns overall, they do not explore the possible underlying mechanisms.

Secondly, Derrien, Frésard, Slabik and Valta (2019) observe that positive average abnormal competitor returns occur when the target firm is public, but not when it is private - looking at 984 horizontal U.S. mergers involving a public target and 7,010 involving a private target occurring between 1990 and 2015 and with a deal value above 10 million dollar. They identify competitors using four-digit SIC codes and an event window of at most five days prior and after the event. They argue that the

difference in case of a public or private target is driven by a signal on industry health: an acquirer - who is assumed to be better informed on industry performance - would prefer a public firm when public firms are undervalued. The acquisition of a public firm therefore involves a signal that similar public firms are undervalued. They reject an anticipation of anti-competitive market power effects or "in-play" effects, based on an absence of statistical significance with SIC-based HHI and future competitor acquisition.

\subsection{Challenges}

The review above identifies the following main challenges to the application of event studies in merger analysis. First, any assumed mechanism would have to be tested explicitly. For instance, the identifying assumption that a positive (negative) abnormal competitor return implies an anticipation of anti-competitive (pro-competitive) effects may fail to hold. When testing any mechanism, good practice dictates that a lack of statistical significance on itself does not prove an absence of effect.

Second, the use of event studies in merger analysis requires the reliable identi- 
fication of competitors. This is not straightforward. As mentioned, the often-used method of relying on industry codes such as SIC does a poor job at identifying antitrust markets (Werden and Williams, 1988; Hoberg and Phillips, 2016). This is because they classify firms based on the supply instead of demand side, are often too broad, hardly reclassify firms as markets evolve and their binary nature imposes transitivity (in which the set of competitors to any two firms has to be identical).

And third, event studies in merger analysis involves the identification of small effects in very noisy data (Werden and Williams, 1989a). This means that event studies have a very low precision when looking at individual mergers or even small samples. In other words, they require a sufficiently large dataset to achieve sufficient statistical power, which many of the existing studies do not have.

In the remainder of this paper I use event studies to look at a large subset of major U.S. mergers that occurred between 1997 and 2017. I deal with the second and third challenges by using a novel application of Hoberg-Phillips data, which can be used to proxy a ranking of competitors to many mergers. I deal with the first challenge by testing whether the cumulative abnormal returns are associated with indicators of market power concerns. I remain agnostic on whether results are additionally driven by any of the other mechanisms.

\section{Data Collection and Cleaning}

I use the Refinitiv SDC Platinum database to identify all major U.S. mergers between January 1997 and December 2017 with a real transaction value above one billion dollar and a publicly-traded target. Using the Hoberg-Phillips TNIC database, I am able to proxy a ranking of competitors to 1,751 of the largest U.S. mergers with a public target. Daily stock market returns of all relevant firms and the S\&P 500 as benchmark stock market index are collected using CRSP data collected from WRDS. Below the data collection and cleaning is discussed in more detail. 


\subsection{Subset of Mergers}

A dataset of all 98,123 transactions between January 1997 and December 2017 with a U.S. firm as target is extracted from the Refinitiv SDC Platinum database. The collected variables include target firm name, acquiring firm name, date of official announcement, transaction value, increase in shareholding, post-transaction shareholding and whether or not the transaction has been completed.

From this dataset, 3,794 transactions are identified that (i) had a transaction value of at least one billion dollar (in December 2017 value), (ii) have been completed, (iii) involved a share acquisition of at least 50 percent and (iv) did not have the acquirer listed as 'shareholders'. Of these, 1,661 transactions had to be dropped because the name of the target firm could not be identified in the Hoberg-Phillips database. In most cases, this is because the target firm is not publicly listed and hence not even included in the Hoberg-Phillips database (which only includes publicly-traded U.S. firms, as discussed below). In some cases however, an absence of identification may be because the names in the Refinitiv SDC Platinum database were not properly matched with those in the Hoberg-Phillips database. This has been checked manually, but with no guarantee that all matches have been correct.

Finally, 382 mergers were dropped because the merging parties had no TNIC score despite both being identified in the Hoberg-Phillips database. This could be because Hoberg and Phillips drop scores if firms are classified as vertically related, discussed below. Excluding these is justified because we are interested in horizontal mergers. Another reason could be an erroneous matching of firm names. Such observations are essentially random noise, which justifies excluding them.

Figure 1 shows the distribution of mergers over the years and real transaction values - separately for all 3,794 transactions and for the final dataset of 1,751 transactions. The left panel illustrates the well-known merger waves: before 2000, before 2008 and until recently. The middle and right panels show that the distribution over the real transaction value is skewed. In both the full and the final dataset, about 
$50 \%$ of mergers have a real transaction value between one and 2.5 billion dollar, $25 \%$ between 2.5 and five billion dollar, $20 \%$ between five and 20 billion dollar and only the remaining five percent above 20 billion dollar. While the distributions of the full and final dataset are relatively similar, the final distribution does have more observations with higher transaction value. This is most likely because the final dataset only includes transactions with a target firm that is publicly traded and higher-valuation firms are more often publicly traded.

Figure 1: Distribution of Mergers
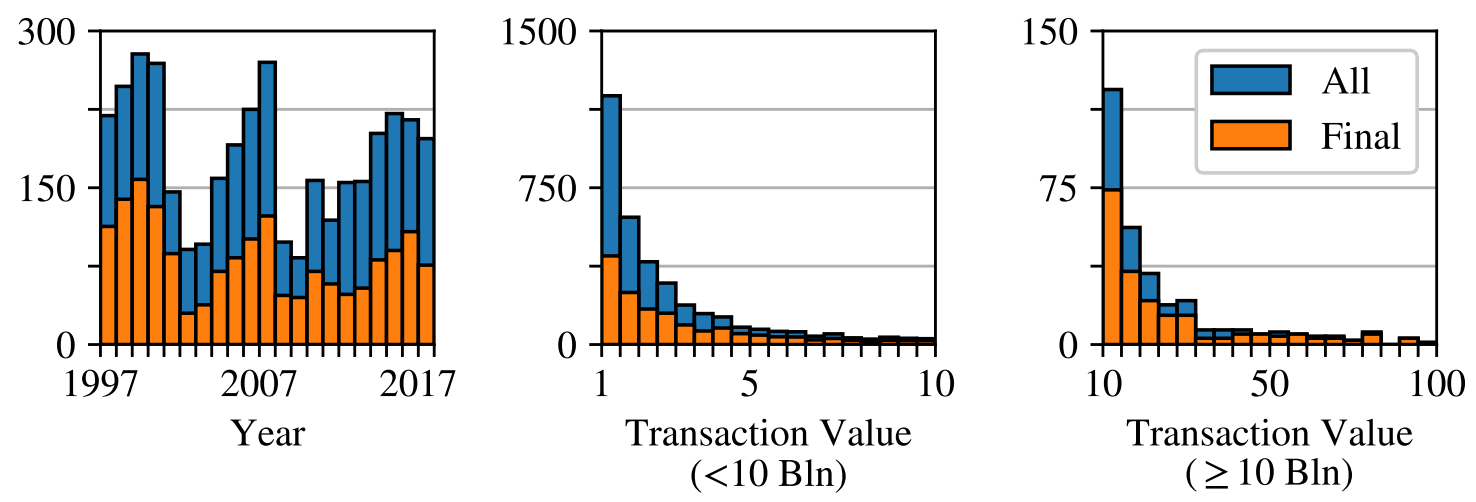

Notes: Distribution of mergers over years and real transaction value, for all U.S. mergers with a real transaction value of at least one billion dollar (in December 2017 value) and for the final dataset used.

\subsection{Hoberg-Phillips TNIC Scores}

The Hoberg-Phillips (2010, 2016) Text-Based Network Industry Classification (TNIC) database consists of yearly matrices with pair-wise firm differentiation scores for all 13,808 publicly-traded U.S. firms from 1996 to 2017. The scores are derived from a text-based analysis of their 10-K business descriptions, which firms submit yearly to the Securities and Exchange Commission and which is legally required to represent a concise and accurate summary of their product offerings. Hoberg and Phillips claim that the TNIC scores capture the degree of competition between two firms, based on the premise that firms with more common vocabulary in their $10-\mathrm{K}$ product 
descriptions are nearer competitors. As such, the TNIC scores can be interpreted as a Hotelling-like product differentiation score: firms with higher TNIC scores have more similar $10-\mathrm{K}$ product descriptions and are therefore closer competitors. ${ }^{3}$

For the purpose of this paper, I identify the most likely competitors as those firms with the highest TNIC score with the target firm. I also vary the lowest admissible rank, to see for which ranks an average effect may be found. An alternative approach would select all firms with a TNIC score above a certain cut-off value. This approach is omitted for two reasons. First, it requires the assumption that TNIC scores are also cardinal instead of only ordinal - which may not hold across industries or years. Second, empirically this approach leads to many mergers with no competitors at all, while at the same time leading to many other mergers with unreasonably many competitors.

TNIC scores have several advantages over industry codes such as SIC. Most importantly, TNIC scores are a continuous measure between zero and one, instead of a binary in-out classification. This allows for a much finer selection of potential competitors than industry codes, which often include many hundreds of firms. Additionally, they are based on product descriptions (demand side) instead of the production process (supply side). Furthermore, because TNIC scores are pair-wise, they are not restricted to transitivity - in which two competitors have to have the same set of other competitors. Finally, TNIC scores are updated yearly, which accommodates changing industry relations following from innovation, dynamic product differentiation or mergers.

It may be that vertically related firms use similar vocabulary for the $10-\mathrm{K}$ product descriptions as well, without competing with each other. Hoberg and Phillips purge the TNIC scores for possible vertical relations as follows. Using Benchmark InputOutput Accounts of the U.S. Economy, they calculate the fraction of inputs that flow between the four-digit SIC codes of each firm pair. If this fraction exceeds one

\footnotetext{
${ }^{3}$ All data is available open-source on www.hobergphillips.tuck.dartmouth.edu. This website also includes further explanations, as well as instructions on how to use and interpret the data.
} 
percent of all inputs, it is assumed that the firms have a vertical relation and their TNIC scores are excluded. This occurs in four percent of all firm pairs. While this approach is not exhaustive in excluding all vertical relations, note that any remaining vertically related firms identified as competitors will bias results downwards, making any positive estimates more conservative.

The Hoberg-Phillips TNIC database provides a convenient differentiation proxy without requiring any market definition or detailed price and quantity data. The main limitation is that it remains a proxy. Because we use the TNIC scores for the ranking of most likely competitors, we risk including weak competitors while excluding strong competitors. Note however, that this cause our estimates to be biased towards zero, making any estimate more conservative. Additionally, the TNIC database only includes publicly-traded U.S. firms. Results are therefore not necessarily externally valid in case of privately-owned or foreign-traded target firms.

\subsection{Stock Market Returns}

The daily returns from 1 January 1995 to 31 December 2018 for all 13,808 firms in the Hoberg-Phillips TNIC database are collected from Center for Research in Security Prices (CRSP), using Wharton Research Data Services (WRDS). CRSP derives the daily returns without dividend as the percentage change in the the daily closing price, excluding any ordinary dividends and certain other regularly taxable dividends from the calculations. In the event study estimation, I drop stocks that are not listed for more than 20 days during the estimation and event window. The S\&P 500 is used as the market index.

\section{Event Study Methodology}

Using event study methodology, the cumulative abnormal return of each of the proxied competitors is calculated around the official merger announcement date. The event 
study methodology is used as follows, which is generally in line with existing literature (Cichello and Lamdin, 2006). For an estimation window of 290 to 51 days prior to the official announcement date of each merger, a linear relationship between stock return $\mathrm{R}_{i t}$ of competitor $i$ to this specific merger on day $t$ and the market index $\mathrm{R}_{m t}$ is estimated using ordinary least squares (OLS):

$$
\mathrm{R}_{i t}=\alpha_{i}+\beta_{i} \mathrm{R}_{m t}+\varepsilon_{i t}
$$

where we omit a subscript indicating the merger. For an event window of 50 days prior and 30 days after the official announcement date, abnormal return $\mathrm{AR}_{i t}$ is calculated for each separate day as the actual return minus the return as predicted by the above market model:

$$
\mathrm{AR}_{i t}=\mathrm{R}_{i t}-\hat{\alpha}_{i}-\hat{\beta}_{i} \mathrm{R}_{m t}
$$

where $\hat{\alpha}_{i}$ and $\hat{\beta}_{i}$ are the coefficient estimates from the market model. Finally, we derive cumulative abnormal return $\mathrm{CAR}_{i t}$ for each competitor $i$ up to day $t$ as the sum of the average abnormal returns in window $\left[t_{0}, t\right]$ :

$$
\mathrm{CAR}_{i t}=\sum_{s=t_{0}}^{t} \mathrm{AR}_{i s}
$$

with starting date $t_{0} \geq-50$. $\mathrm{CAR}_{i t}$ has a straightforward interpretation: it shows for each competitor $i$ to a merger how much more cumulative return it has gotten since $t_{0}$ than what would be expected based on its previous performance.

$\mathrm{CAR}_{i t}$ is derived for those firms proxied as closest competitors to each of the 1,751 mergers, based on a TNIC-based ranking. The amount of observations per day is therefore 1,751 times the lowest admissible rank. This allows us to estimate the average and confidence interval of the cumulative abnormal returns of competitors for each day around the official merger announcement. 
Note that market awareness of the upcoming merger may occur already in the run-up to the official merger announcement. News of the merger may leak out or markets may anticipate such a move. This is why the estimation window runs until 51 days prior to the official announcement and the event window starts at most 50 days prior to the announcement. This is in line with the literature discussed. The trade-off is that setting the cut-off earlier reduces the risk of excluding merger effects from the event window, but increases noise and vulnerability to structural breaks in the estimated market model - and vice versa when setting the cut-off later.

One limitation of using event studies on daily data is that the data may be nonsynchronous, with many stocks traded only infrequently. This may cause $\hat{\alpha}_{i}$ and $\hat{\beta}_{i}$ in the market model to be biased and inconsistent. I therefore use the non-synchronicity adjusted coefficients as developed by Scholes and Williams (1977) - and as also used by Duso, Gugler and Yurtoglu (2011) and others. Scholes and Williams take

$$
\hat{\beta}_{i}^{\mathrm{Adj}}=\frac{\hat{\beta}_{i}^{-}+\hat{\beta}_{i}+\hat{\beta}_{i}^{+}}{1+2 \hat{\rho}_{m}},
$$

where $\hat{\beta}_{i}^{\text {Adj }}$ is the adjusted slope now used in deriving the abnormal return, $\hat{\beta}_{i}^{-}, \hat{\beta}_{i}$ and $\hat{\beta}_{i}^{+}$the slopes as derived in the OLS market model using respectively the lagged, current and leading market return and $\hat{\rho}_{m}$ the estimated autocorrelation coefficient for the market index. The adjusted intercept is then derived as

$$
\hat{\alpha}_{i}^{\mathrm{Adj}}=\bar{R}_{i}-\hat{\beta}_{i}^{\mathrm{Adj}} \bar{R}_{m}
$$

where $\bar{R}_{i}$ and $\bar{R}_{m}$ are the average stock and market returns during the estimation window. The Scholes-Williams adjustment ensures consistency whenever stocks are not traded frequently, while having little effect on the estimates for actively traded stocks (see also MacKinlay, 1997, p. 39). Results without the Scholes-Williams adjustment are comparable but generally more noisy, and therefore not reported. 


\section{Results}

Average $\mathrm{CAR}_{i t}$ and the associations are derived using robust regression (Berk, 1990; Hamilton, 1991), with standard errors clustered per merger. Robust regression has the benefit over OLS in that it reduces the weight of observations that disproportionately affect the estimation, reducing the vulnerability to outliers. A sensitivity check later on shows that results are also conservative relative to OLS.

Figure 2 plots the average and $95 \%$ confidence interval for all $\mathrm{CAR}_{i t}$ for the three closest competitors, taking $t_{0}=-50$ as the start of the event window. Results clearly show a positive average cumulative abnormal competitor return of up to one percent around the time of the merger announcement. In other words, financial markets anticipate on average a higher discounted future cash flow for competitors following a merger announcement. Moreover, Figure 3 shows that the average cumulative abnormal returns are only positive for firms ranked close to the target.

Figure 2: Estimated Average $\mathrm{CAR}_{i t}$ Around Event Date

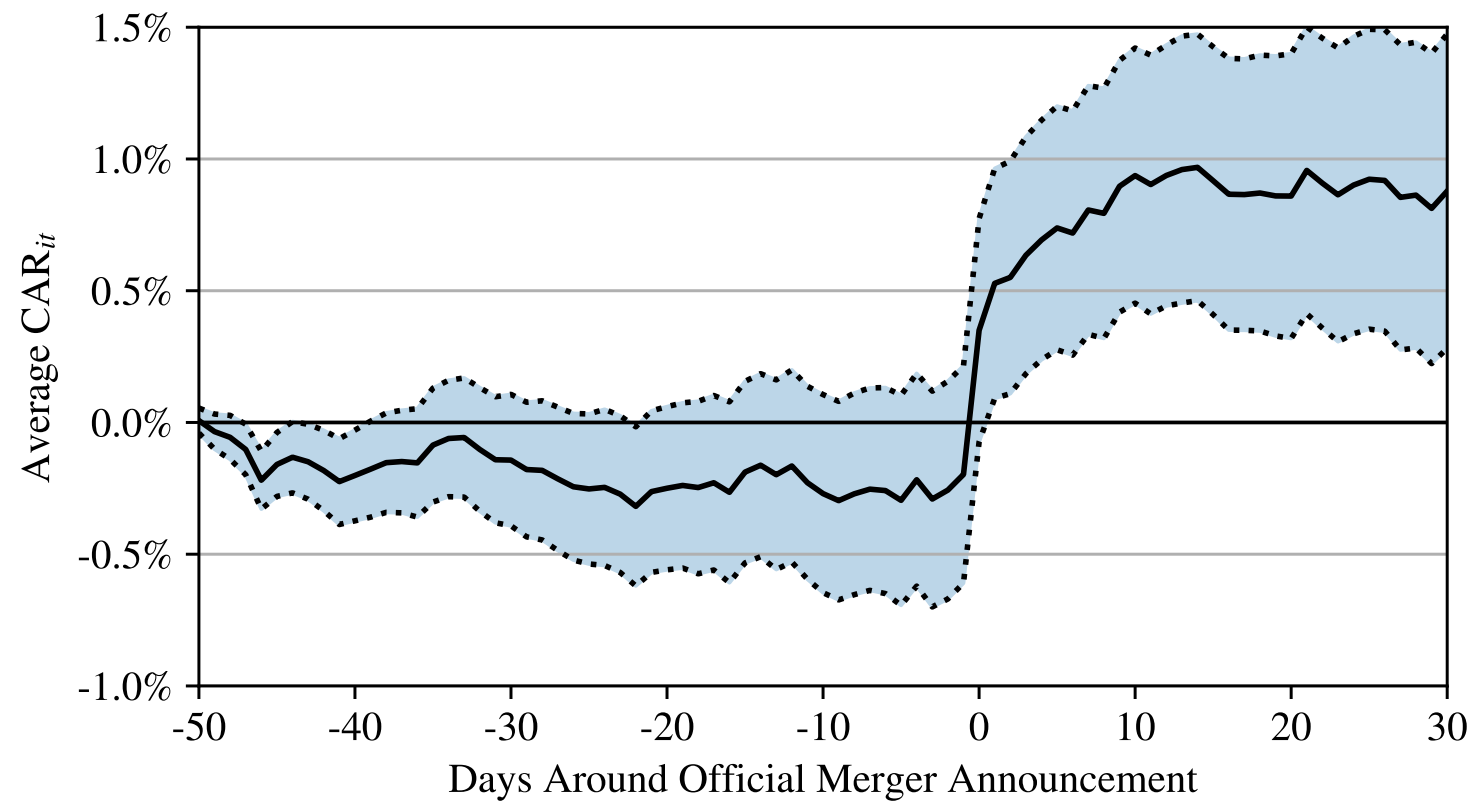

Notes: Average cumulative abnormal returns for three closest competitors, for event window starting at $t_{0}=-50$. Estimate and $95 \%$ confidence interval are based on robust regression with merger-clustered standard errors. 
Figure 3: Estimated Average $\mathrm{CAR}_{i t}$ for Different Ranks

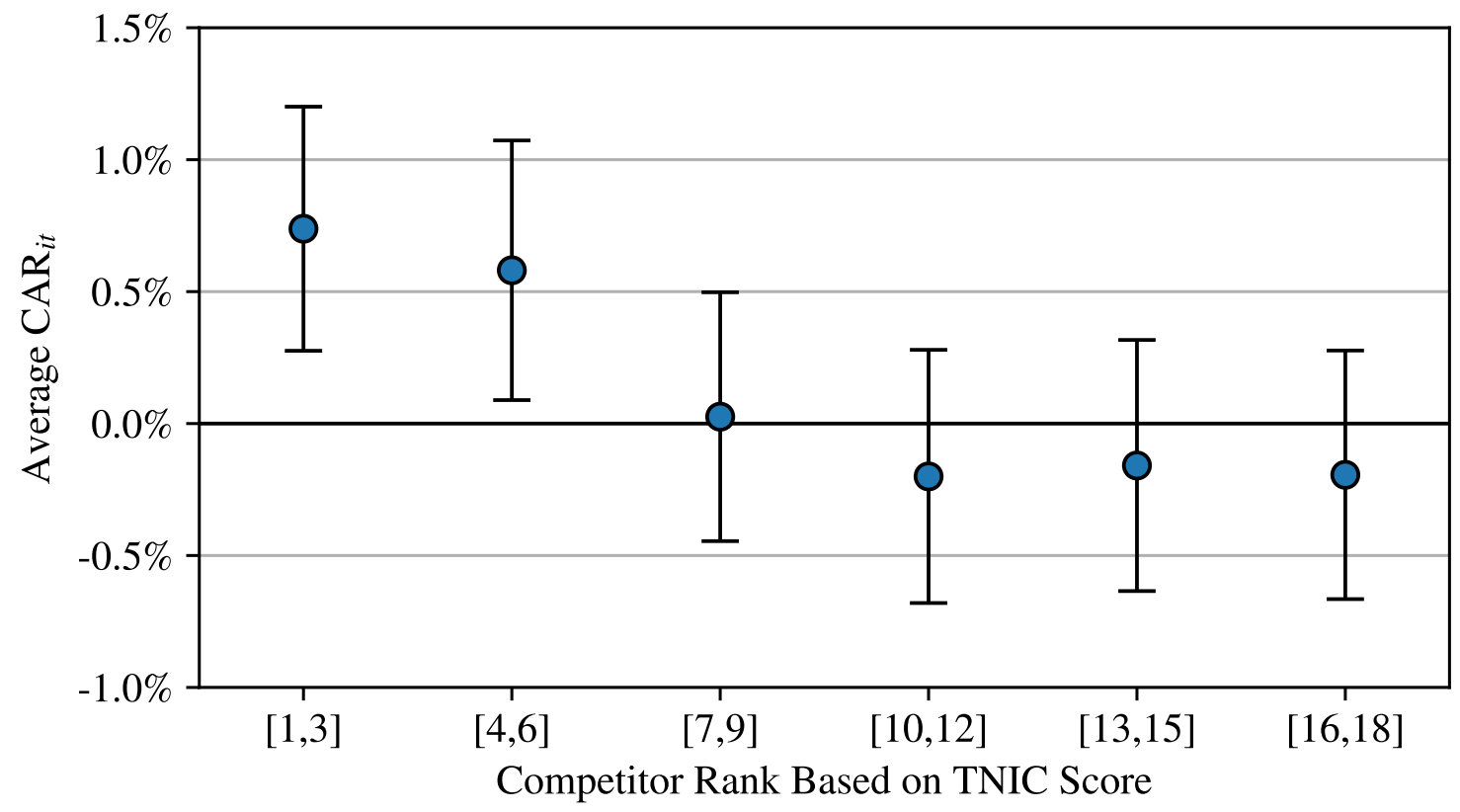

Notes: Average cumulative abnormal returns for different ranks, for event window $t \in[-50,5]$. Estimate and $95 \%$ confidence interval are based on robust regression with merger-clustered standard errors.

Existing work often interprets such results as an anticipation of anti-competitive effects, based on the assumed inverse relationship between competitor returns prices and consumer welfare. To test this, I regress the cumulative abnormal returns on a TNIC-based Herfindahl-Hirschman Index (HHI) for market concentration for each competitor, which serves as an indication of market power concerns. This TNICbased HHI is provided by Hoberg and Phillips and is derived as a conventional HHI by summing the squared market shares of all firms within a market. ${ }^{4}$

Table 2 shows that there is indeed an association between the TNIC-based SIC3granularity HHI of each competitor. This suggests empirically that competitors in markets where there is potentially a bigger market power concern experience a larger

\footnotetext{
${ }^{4}$ Hoberg and Phillips define the relevant market for each firm as all other firms with a TNIC score above a certain threshold. They set this threshold such that the granularity is equivalent to threedigit SIC codes. This means that if you pick two random firms, they have the same probability of being in the same market as under three-digit SIC codes. See www.hobergphillips.tuck.dartmouth.edu for this data and further use-instructions.
} 
Table 2: Results Regressing $\mathrm{CAR}_{i t}$ on Market Concentration Proxy

\begin{tabular}{lccccc}
\hline Event Window & {$[-50,5]$} & {$[-40,5]$} & {$[-30,5]$} & {$[-20,5]$} & {$[-10,5]$} \\
\hline \multirow{2}{*}{ TNIC3 HHI } & $\begin{array}{ccccc}0.0418^{* * *} \\
(0.0152)\end{array}$ & $\begin{array}{c}0.0371^{*} \\
(0.0193)\end{array}$ & $\begin{array}{c}0.0467^{* * *} \\
(0.0115)\end{array}$ & $\begin{array}{c}0.0302^{* * *} \\
(0.0091)\end{array}$ & $\begin{array}{c}0.0137^{*} \\
\end{array}$ \\
& 0.0017 & 0.0051 & 0.0011 & 0.0013 & $0.0034^{* *}$ \\
Constant & $(0.0032)$ & $(0.0041)$ & $(0.0025)$ & $(0.0019)$ & $(0.0014)$ \\
& & & & & \\
\hline Observations & 5,134 & 5,127 & 5,152 & 5,138 & 5,127 \\
\hline
\end{tabular}

Notes: Robust regression estimates for cumulative abnormal return for three closest competitors for different event windows, controlling for competitor TNIC-based SIC3-granularity HHI. Merger-clustered standard errors are in parentheses. ${ }^{* * *}$, ** and ${ }^{*}$ indicate statistical significance at $1 \%, 5 \%$ and $10 \%$ respectively.

abnormal return following a merger announcement. While this result does not exclude additional mechanisms, it does suggest that results are at least in part driven by an anticipation of anti-competitive market power effects. Note finally that the difference in amount of observations is driven by the fact that robust regression drops observations from the total of 5,253 observations that have a particularly disproportionate effect on the estimation.

An additional possible mechanism is the "in-play" effect, in which the announcement signals that similar firms are more likely to be acquired in the future. Tables 3 and 4 show the association between the cumulative abnormal returns and whether the competitor itself or any of the six closest competitors becomes a target in the subsequent 12 or 60 months (and in this sample). There is a general absence of statistically significant results, apart from the narrow event window of 10 days prior and five days after the announcement date. It therefore remains unclear whether this mechanism is very prominent. Note again that the difference in amount of observations is driven by the fact that robust regression drops apparent outliers, from the total of 5,025 in case of 12 months and 4,026 in case of 60 months (which are also less than the previous 5,253 observations, because of less available data on the future). 
Table 3: Results Regressing $\mathrm{CAR}_{i t}$ on Future Competitor Merger

\begin{tabular}{lcccccc}
\hline Event Window & {$[-50,5]$} & {$[-30,5]$} & {$[-10,5]$} & {$[-50,5]$} & {$[-30,5]$} & {$[-10,5]$} \\
\hline Competitor & -0.00475 & 0.0060 & $0.0107^{* *}$ & & & \\
Merges 12M & $(0.0095)$ & $(0.0071)$ & $(0.0046)$ & & & \\
Competitor & & & & 0.0046 & 0.0085 & $0.0080^{* *}$ \\
Merges 60M & & & $(0.0067)$ & $(0.0053)$ & $(0.0031)$ \\
& & & & & & \\
Constant & $0.0089^{* * *}$ & $0.0078^{* * *}$ & $0.0054^{* * *}$ & $0.0080^{* * *}$ & $0.0068^{* * *}$ & $0.0048^{* * *}$ \\
& $(0.0025)$ & $(0.0019)$ & $(0.0011)$ & $(0.0030)$ & $(0.0023)$ & $(0.0014)$ \\
\hline & & & & & & \\
\hline Observations & 4,914 & 4,930 & 4,907 & 3,936 & 3,955 & 3,931 \\
\hline
\end{tabular}

Notes: Robust regression estimates for cumulative abnormal return for three closest competitors for different event windows, controlling for whether the competitor mergers within the next 12 or 60 months. Merger-clustered standard errors are in parentheses. ${ }^{* * *},{ }^{* *}$ and ${ }^{*}$ indicate statistical significance at $1 \%, 5 \%$ and $10 \%$ respectively.

Table 4: Results Regressing $\mathrm{CAR}_{i t}$ on Any Future Competitor Mergers

\begin{tabular}{lcccccc}
\hline Event Window & {$[-50,5]$} & {$[-30,5]$} & {$[-10,5]$} & {$[-50,5]$} & {$[-30,5]$} & {$[-10,5]$} \\
\hline A Competitor & 0.0012 & 0.0027 & 0.0039 & & & \\
Merges 12M & $(0.0058)$ & $(0.0046)$ & $(0.0027)$ & & & \\
A Competitor & & & & & & \\
Merges 60M & & & $(0.0010$ & -0.0020 & 0.0035 \\
& & & & $(0.0044)$ & $(0.0025)$ \\
Constant & $0.0084^{* * *}$ & $0.0076^{* * *}$ & $0.0050^{* * *}$ & $0.0083^{*}$ & $0.0071^{* *}$ & $0.0041^{* *}$ \\
& $(0.0028)$ & $(0.0021)$ & $(0.0012)$ & $(0.0043)$ & $(0.0033)$ & $(0.0019)$ \\
\hline Observations & 4,915 & 4,930 & 4,909 & 3,936 & 3,953 & 3,932 \\
\hline
\end{tabular}

Notes: Robust regression estimates for cumulative abnormal return for three closest competitors for different event windows, controlling for whether any of the six closest competitors mergers within the next 12 or 60 months. Merger-clustered standard errors are in parentheses. ${ }^{* * *},{ }^{* *}$ and ${ }^{*}$ indicate statistical significance at $1 \%, 5 \%$ and $10 \%$ respectively. 
Note that the proxy for the anticipation of anti-competitive effects or "in-play" effects may still be insufficient to fully capture these mechanisms. Specifically, the TNIC-based HHI has the limitation that it only considers publicly-traded U.S. firms, while many markets also include privately-owned or foreign-traded firms. This is only a concern however when abnormal competitor returns are somehow lower in markets with more privately-owned or foreign firms (and hence an artificially lower TNICbased HHI). Additionally, any abnormal competitor returns may still, at least in part, be driven by the signalling on industry health and prospects as well as countervailing mechanisms.

The choice for robust regression instead of OLS reduces the vulnerability of the estimates to outliers during the event window, but is at the same time much less conventional. Figure 4 shows the estimates when using OLS instead of robust regression. Note that the estimated average cumulative abnormal return now jumps with

Figure 4: Estimated Average $\mathrm{CAR}_{i t}$ Using OLS

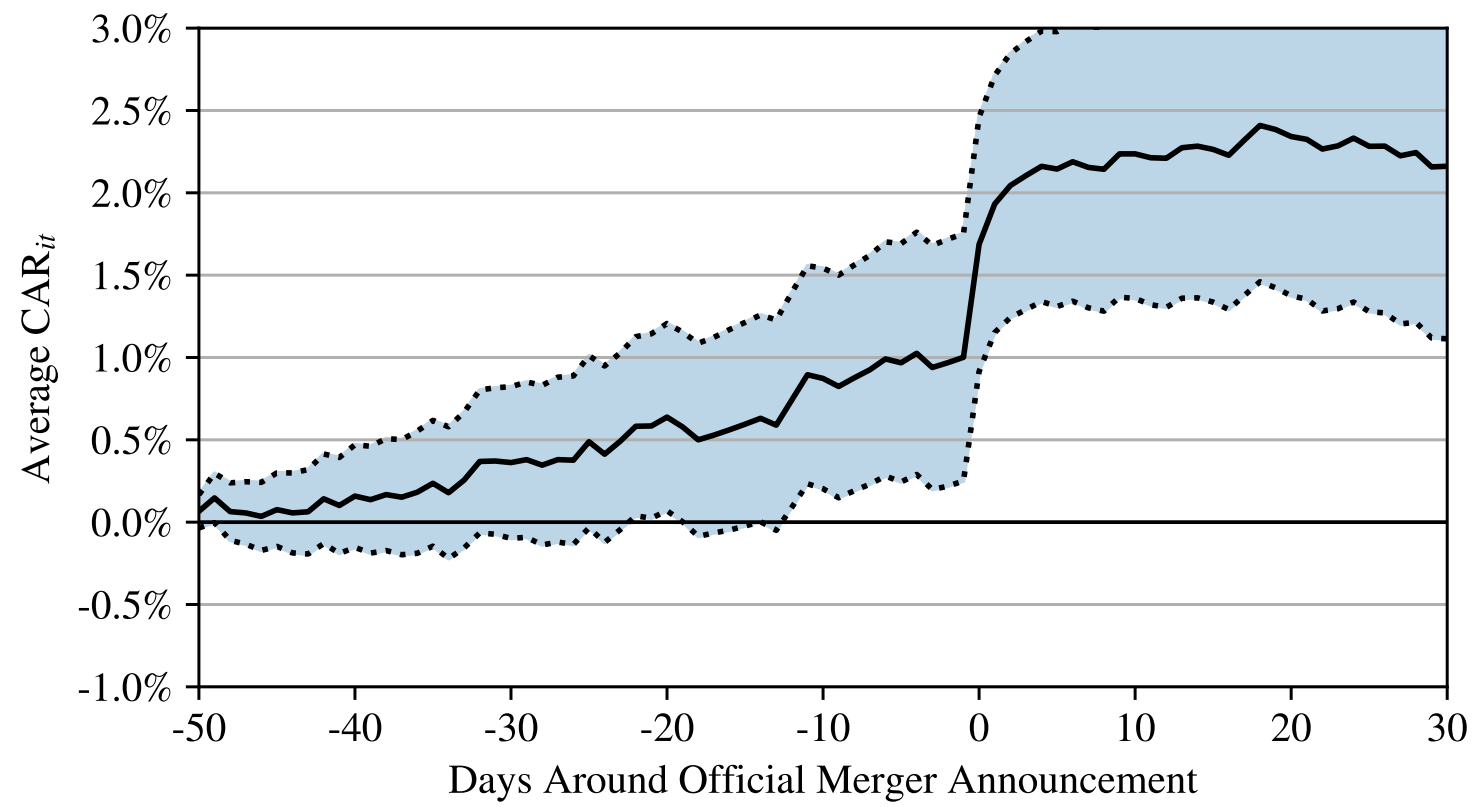

Notes: Average cumulative abnormal returns for three closest competitors, for event window starting at $t_{0}=-50$. Estimate and $95 \%$ confidence interval are based on ordinary least squares regression with merger-clustered standard errors. 
more than one percent around the date of the merger announcement. The estimate now also increases in the run-up to the official announcement date. Additionally, the standard errors under OLS are larger than under robust regression. The difference is driven by the fact that robust regression reduces the weight of observations that heavily affect the estimation - in the most extreme case dropping the observation. This makes OLS much more vulnerable to outliers than robust regression.

\section{Concluding Remarks}

There is a growing concern that U.S. merger control may have been too lenient. Empirical evidence remains limited however, mostly because of the limited data availability necessary for proper ex post merger reviews. Event studies have been proposed as a simple alternative to acquire at least some empirical insights into the anticipated competitive effects of mergers.

Limitations notwithstanding, event studies have several advantages over alternative empirical methods to analyse the competitive effects of mergers. For instance, compared to case-specific ex post merger reviews, event studies readily account for both prices and non-price competition by looking directly at (anticipated) future profitability. By looking at stock prices, they also account for long run anticipated effects. Finally, the data requirements for event studies are a lot lower than proper ex post merger reviews - which generally requires very granular and often proprietary data.

More specifically, this paper shows how event studies can be used as supplementary or circumstantial empirical evidence on the concern of insufficient merger control - at least in the aggregate. I am able to overcome common challenges in the use of event studies in merger analysis by using a novel application of Hoberg-Phillips TNIC data. This application allows me to readily proxy the most likely competitors to a large subset of the largest U.S. mergers between 1997 and 2017.

I find that the most likely competitors benefit on average from a major merger 
announcement. The association with a TNIC-based HHI further suggests that results are at least in part driven by an anticipation of anti-competitive effects. This provides the circumstantial evidence that U.S. merger control has indeed been too lenient even though event studies may not say much about individual mergers, for which case-specific ex ante or ex post merger reviews seem indispensable.

\section{References}

Angrist, J.D. and Pischke, J.S. (2010) "The Credibility Revolution in Empirical Economics: How Better Research Design is Taking the Con out of Econometrics", Journal of Economic Perspectives, 24(2), 3-30

Autor, D., Dorn, D., Katz, L.F., Patterson, C. and Van Reenen, J. (forthcoming) "The Fall of the Labor Share and the Rise of Superstar Firms", Quarterly Journal of Economics

Baker, J. (2019) The Antitrust Paradigm. Restoring a Competitive Economy, Harvard University Press, Cambridge, Massachusetts

Basu, S. (2019) "Are Price-Cost Markups Rising in the United States? A Discussion of the Evidence", Journal of Economic Perspectives, 33(3), 3-22

Berk, R. (1990) "A Primer on Robust Regression", in: Fox, J. and Long, J.S. (eds.), Modern Methods of Data Analysis, SAGE Publishing, Newbury Park, California

Bernile, G. and Lyandres, E. (2019) "The Effects of Horizontal Merger Operating Efficiencies on Rivals, Customers, and Suppliers", Review of Finance, 23(1), 117-160 Cichello, M. and Lamdin, D.J. (2006) "Event Studies and the Analysis of Antitrust", International Journal of the Economics of Business, 13(2), 229-245

De Loecker, J. and Eeckhout, J. (2018) "Global Market Power", NBER Working Paper, No. 24768 
De Loecker, J., Eeckhout, J. and Unger, G. (forthcoming) "The Rise of Market Power and the Macroeconomic Implications", The Quarterly Journal of Economics

Derrien, F., Frésard, L., Slabik, V. and Valta, P. (2019) "The Revaluation of Industry Assets Following Acquisitions of Public or Private Targets", Working Paper, SSRN 2960576

Duso, T., Neven, D.J. and Röller, L.H. (2007) "The Political Economy of European Merger Control: Evidence Using Stock Market Data", The Journal of Law and Economics, 50(3), 455-489

Duso, T., Gugler, K. and Szücs, F. (2013) "An Empirical Assessment of the 2004 EU Merger Policy Reform", The Economic Journal, 123(572), 596-619

Duso, T., Gugler, K. and Yurtoglu, B. (2010) "Is the Event Study Methodology Useful for Merger Analysis? A Comparison of Stock Market and Accounting Data", International Review of Law and Economics, 30(2), 186-192

Duso, T., Gugler, K. and Yurtoglu, B. (2011) "How Effective is European Merger Control?", European Economic Review, 55(7), 980-1006

Eckbo, B.E. (1983) "Horizontal Mergers, Collusion, and Stockholder Wealth", Journal of Financial Economics, 11(1-4), 241-273

Eckbo, B.E. and Wier, P. (1985) "Antimerger Policy Under the Hart-Scott-Rodino Act: A Reexamination of the Market Power Hypothesis", The Journal of Law and Economics, 28(1), 119-149

Fama, E.F., Fisher, L., Jensen, M.C. and Roll, R. (1969) "The Adjustment of Stock Prices to New Information", International Economic Review, 10(1), 1-2

Farrell, J. and Shapiro, C. (1990) "Horizontal Mergers: an Equilibrium Analysis", The American Economic Review, 80(1) 107-126

Fee, C.E. and Thomas, S. (2004) "Sources of Gains in Horizontal Mergers: Evidence From Customer, Supplier, and Rival Firms", Journal of Financial Economics, 74(3), 
$423-460$

Fridolfsson, S.O. and Stennek, J. (2010) "Industry Concentration and Welfare: On the Use of Stock Market Evidence from Horizontal Mergers", Economica, 77(308), 734-750

Grullon, G., Larkin, Y. and Michaely, R. (2019) "Are US Industries Becoming More Concentrated?" Review of Finance, 23(4), 697-743

Gutiérrez, G. and Philippon, T. (2018) "How EU Markets Became More Competitive than US Markets: A Study of Institutional Drift", NBER Working Paper No. W24700 Hamilton, L.C. (1991) "How Robust is Robust Regression?", Stata Technical Bulletin 2, 21-26

Hoberg, G. and Phillips, G. (2010) "Product Market Synergies and Competition in Mergers and Acquisitions: A Text-Based Analysis", The Review of Financial Studies, 23(10), 3773-3811

Hoberg, G. and Phillips, G. (2016) “Text-Based Network Industries and Endogenous Product Differentiation", Journal of Political Economy, 124(5), 1423-1465

Leibenstein, H. (1966) "Allocative Efficiency vs. 'X-Efficiency'", The American Economic Review, 392-415

Kwoka, J. (2015) Mergers, Merger Control, and Remedies. A Retrospective Analysis of US Policy, The MIT Press, Cambridge, Massachusetts

Kwoka, J. and Gu, C. (2015) "Predicting Merger Outcomes: The Accuracy of Stock Market Event Studies, Market Structure Characteristics, and Agency Decisions", The Journal of Law and Economics, 58(3), 519-543

MacKinlay, A.C. (1997) "Event Studies in Economics and Finance", Journal of Economic Literature, 35(1), 13-39

McAfee, R.P. and Williams, M.A. (1988) "Can Event Studies Detect Anticompetitive 
Mergers?", Economics Letters, 28(2), 199-203

Malmendier, U., Moretti, E. and Peters, F.S. (2018) "Winning by Losing: Evidence on the Long-Run Effects of Mergers", The Review of Financial Studies, 31(8), 32123264

Moeller, S.B., Schlingemann, F.P. and Stulz, R.M. (2005) "Wealth Destruction on a Massive Scale? A Study of Acquiring-Firm Returns in the Recent Merger Wave", The Journal of Finance, 60(2), 757-782

Motta, M. (2004) Competition Policy: Theory and Practice, Cambridge University Press, Cambridge, United Kingdom

Philippon, T. (2019) The Great Reversal. How America Gave Up On Free Markets, Harvard University Press, Cambridge, Massachusetts

Scholes, M. and Williams, J. (1977) "Estimating Betas from Nonsynchronous Data", Journal of Financial Economics, 5(3), 309-327

Servaes, H. and Tamayo, A. (2013) "How do Industry Peers Respond to Control Threats?", Management Science, 60(2), 380-399

Shahrur, H. (2005) "Industry Structure and Horizontal Takeovers: Analysis of Wealth Effects on Rivals, Suppliers, and Corporate Customers", Journal of Financial Economics, 76(1), 61-98

Shapiro, C. (2018) "Antitrust in a Time of Populism", International Journal of Industrial Organization, 61, 714-748

Shapiro, C. (2019) "Protecting Competition in the American Economy: Merger Control, Tech Titans, Labor Markets", Journal of Economic Perspectives, 33(3), 69-93

Song, M.H. and Walkling, R.A. (2000) "Abnormal Returns to Rivals of Acquisition Targets: A Test of the Acquisition Probability Hypothesis", Journal of Financial Economics, 55(2), 143-171 
Stiebale, J. and Szücs, F. (2019) "Mergers and Market Power: Evidence From Rivals' Responses in European Markets", DICE Discussion Paper No. 323

Stillman, R. (1983) "Examining Antitrust Policy Towards Horizontal Mergers", Journal of Financial Economics, 11(1-4), 225-240

Syverson, C. (2019) "Macroeconomics and Market Power: Facts, Potential Explanations and Open Questions", Journal of Economic Perspectives, 33(3), 23-43

Werden, G.J. (1988) “The Divergence of SIC Industries from Antitrust Markets: Some Evidence from Price Fixing Cases", Economics Letters, 28(2), 193-197

Werden, G.J. and Williams, M.A. (1989a) "The Role of Stock Market Studies in Formulating Antitrust Policy Toward Horizontal Mergers", Quarterly Journal of Business and Economics, 28(4), 3-21

Werden, G.J. and Williams, M.A. (1989b) "The Role of Stock Market Studies in Formulating Antitrust Policy Toward Horizontal Mergers: Reply", Quarterly Journal of Business and Economics, 39-42

Wollmann, T.G. (2019) "Stealth Consolidation: Evidence from an Amendment to the Hart-Scott-Rodino Act", American Economic Review: Insights, 1(1), 77-94 